Research Paper

\title{
Appraisal of photoelectrocatalytic oxidation of glucose and production of high value chemicals on nanotube $\mathrm{Ti} / \mathrm{TiO}_{2}$ electrode
}

\author{
Rodrigo Monteiro Fabrao, Juliana Ferreira de Brito, Jose Luiz da Silva, \\ Nelson Ramos Stradiotto, Maria Valnice Boldrin Zanoni* \\ UNESP, Institute of Chemistry, R. Francisco Degni 55, 14800-060 Araraquara, SP, Brazil
}

\section{A R T I C L E I N F O}

\section{Article history:}

Received 20 June 2016

Received in revised form 11 October 2016

Accepted 24 October 2016

Available online 29 October 2016

\section{Keywords:}

Products generation

$\mathrm{TiO}_{2}$ nanotubes

Photoelectrocatalysis

Glucose conversion

\begin{abstract}
A B S T R A C T
The present work describes an alternative process for glucose oxidation via photoelectrocatalytic technique using $\mathrm{Ti} / \mathrm{TiO}_{2}$ nanotubes as photoanodes. Under optimum experimental conditions, which entailed $10.0 \mathrm{mM}$ glucose in $0.1 \mathrm{M} \mathrm{Na}_{2} \mathrm{SO}_{4}, \mathrm{pH} 6.60, \mathrm{E}_{\mathrm{app}}=1.5 \mathrm{~V}$ and $\mathrm{UV}$ irradiation we were able to convert $78 \%$ of glucose following 180 min of photoelectrocatalysis. Out of that, only $28 \%$ was, in effect, converted to $\mathrm{CO}_{2}$ as detected by total organic carbon removal. During the course of the process, a large part of this glucose was found to be transformed into products among them including Arabinose, Arabinitol, 4ketoglicose, glucohexodialdose, Glucone- $\delta$-Lactone, 6-deoxiglucose and Gluconic Acid, where this detection was aided by ion-exchange chromatography with amperometric detection and gas chromatography-mass spectra. The results thus essentially demonstrate that photoelectrocatalys can be considered a suitable alternative in fostering glucose conversion, in aqueous medium, to high added value products using a relatively simple and economic method.
\end{abstract}

(c) 2016 Elsevier Ltd. All rights reserved.

\section{Introduction and Objectives}

The production of ethanol used as a renewable source of energy is essentially considered one of the major activities of bioeconomy in Brazil and could represent a huge potential for the country's development, if appropriate measures, such as a more efficient use of biomass, adequate processing of by-products and co-products, are harnessed and incorporated in new industrial inputs. The production of sugarcane in the country has now reached an impressive value of around 610 million ton/year. Although the product is known to be primarily used in the manufacture of ethanol and sugar [1], its production process also leads to the generation of $270 \mathrm{~kg}$ of bagasse and $800 \mathrm{~L}$ of vinasse per ton as residue of the processed sugarcane [2]. The bagasse basically comprises cellulose (25-47\%) and hemicellulose (20-35\%), which can be hydrolyzed into glucose [1]. Part of the bagasse is reused in industry as fuel for boilers and as fertilizer in sugarcane plantation. Oddly enough though, the greater part of this biomass is often discarded, generating large amounts of organic waste and environmental problems [1-3].

\footnotetext{
* Corresponding author.

E-mail address: mvboldrin@gmail.com (M.V.B. Zanoni).
}

Aiming at turning around the trend and improving the process towards a more sustainable production while transforming the biomass into high-value chemicals, the sugarcane production process has attracted a wider global interest thanks to the rise in demand for different methods capable of converting biomass into reusable products [3-11]. Interestingly, among the wide range of methods being tested and used, glucose oxidation has received a greater attention through the use of enzyme, microbe, coenzyme, redox mediator, metal complex, metal oxide nanoparticles as catalysts and photocatalysts [12].

Indeed, most of the proposed methods are mainly based on hydrogen production with the exception of preliminary investigations that deal with the conversion of cellulose via photocatalysis $[9,13]$. An example worth mentioning is the study published by Colmenares et al., which, in a short communication, reported that powered $\mathrm{TiO}_{2}$ is capable of promoting glucose oxidation to glucaric/gluconic acid and arabitol products by photocatalysis [14-18].

Accorgind to Bessegato and coworkers [19], the advances in material science are close related to the advances in photoelectrocatalysis, due the advent of nanotechnology producing more efficient electrodes. And, among the several $\mathrm{TiO}_{2}$ morphologies possible, the nanotubes of titanium dioxide exhibit excellent stability, large internal surface area, and excellent electron percolation pathways for vectorial charge transfer. In addition, 
Ghicov and Schmuki [20] affirm that for self-organized $\mathrm{TiO}_{2}$ nanotube arrays their self-aligned nature leads to a significant enhancement of the performance when used in photoelectrochemistry, photocatalysis, dye-sensitized solar cells, or electrochromic devices. In addition to this, the vertically oriented nanotube arrays formation can be achieved by a simple one-step electrochemical self-assembly process, controlling the tube length or diameter just adjusting the anodization parameters.

Photoelectrocatalysis is mainly based on the irradiation of a biased semiconductor with a potential gradient relatively higher than its flat band potential [19,21,22]. The increase in band bending within the $\mathrm{TiO}_{2}$ particles is found to promote electrons depletion and enrichment of holes on the $\mathrm{Ti} / \mathrm{TiO}_{2}$ surface, while the photogenerated electrons on the anode are redirected to the cathode through the conventional electrochemical system [19]. By so doing, the process is seen to undergo improvement once recombination is minimized and strongly used in the oxidation of organic [21,22] and inorganic [23] waste, disinfection [24] and energy production [25]. Photoelectrocatalysis has also been used in glucose degradation aiming at hydrogen production [26-28].

Works in literature reports that glucose can be converted via photochemical and electrochemical methods into Gluconic and Glucaric Acids, Arabinose, Arabitol, Erythrose among others substances $[14,15,29,30]$ widely used in food and pharmaceutical industries [9,14,31,32]. Gluconic acid and its derivates have a market value around US\$8.50/kg in pharmaceutical and food industries [33].

Nonetheless, reports about photoelectrocatalytic conversion of glucose in titanium dioxide nanotubes $\left(\mathrm{Ti} / \mathrm{TiO}_{2}-\mathrm{NT}\right)$ focusing on the monitoring of sub-products, are yet a scarce reality.

The core aim of the present work lies in assessing the efficiency of $\mathrm{Ti} / \mathrm{TiO}_{2}$ nanotube electrodes in the conversion of glucose to highvalue chemicals via the use of the photoelectrocatalysis technique. The glucose oxidation kinetics parameters were evaluated through ionic exchange chromatography with amperometric detection, total organic carbon and gas chromatography with mass spectrometry techniques applied towards the assessment of the effectiveness and efficacy of the proposed method.

\section{Experimental part}

\section{1. $\mathrm{Ti} / \mathrm{TiO}_{2}-\mathrm{NT}$ electrode preparation}

The electrode was prepared by anodic oxidation [21] of titanium plate $(4.0 \times 4.0 \times 0.25 \mathrm{~cm}$, Sigma-Aldrich, $98 \%)$. This plate was abraded and cleaned with acetone, isopropanol and water for $20 \mathrm{~min}$, respectively. Following the treatment, the plate was then dried with nitrogen gas and transferred as anode into an electrochemical reactor, containing aqueous solution of $0.1 \mathrm{M}$ $\mathrm{NaH}_{2} \mathrm{PO}_{4}+0.3 \% \mathrm{HF}(\mathrm{w} / \mathrm{w})$ as supporting electrolyte, and a ruthenium plate used as cathode. A potential ramp of $2.0 \mathrm{~V} \mathrm{~min}^{-1}$ at $20 \mathrm{~V}$ was applied to this system for $2 \mathrm{~h}$. After anodization, the Ti/ $\mathrm{TiO}_{2}$-NT electrode was washed with deionized water, subsequently dried in $\mathrm{N}_{2}$ and annealed at $450{ }^{\circ} \mathrm{C}$ for $2 \mathrm{~h}$.

\subsection{Electrode characterization}

The $\mathrm{Ti} / \mathrm{TiO}_{2}-\mathrm{NT}$ electrode was characterized by its physical structure through X-Ray diffraction analysis (Rigaku, model Rink 2000). The structure and morphology were analyzed by field emission scanning electron microscopy (FE-SEM) using a Zeiss model Supra 35 equipped with an energy dispersive X-ray (EDX) spectrometer. The photoactivity of the electrode was evaluated through linear scan voltammograms carried out from -0.20 to $1.5 \mathrm{~V}$ vs $\mathrm{Ag} / \mathrm{AgCl}$. Diffuse reflectance spectrum was conducted in a Perkin Elmer Lambda 1050 dual beam spectrophotometer UV/VIS/ NIR with integrating sphere.

\subsection{Photoelectrochemical Reactor}

The photoelectrocatalytic oxidation was performed in a $250 \mathrm{~mL}$ electrochemical reactor equipped with a reference electrode $(\mathrm{Ag} /$ $\mathrm{AgCl}, \mathrm{KCl}$ sat.), working electrode $\left(\mathrm{Ti} / \mathrm{TiO}_{2}-\mathrm{NT}\right)$ and a counter electrode (Pt gauze). A commercial $125 \mathrm{~W}$ high pressure mercury lamp without the bulb was inserted vertically in a quartz glass bulb in the center of the reactor. The system was kept at a constant temperature of $19^{\circ} \mathrm{C}$. All the photoelectrochemical measurements were carried out in an autolab PGSTAT-302 mpotentiostat/
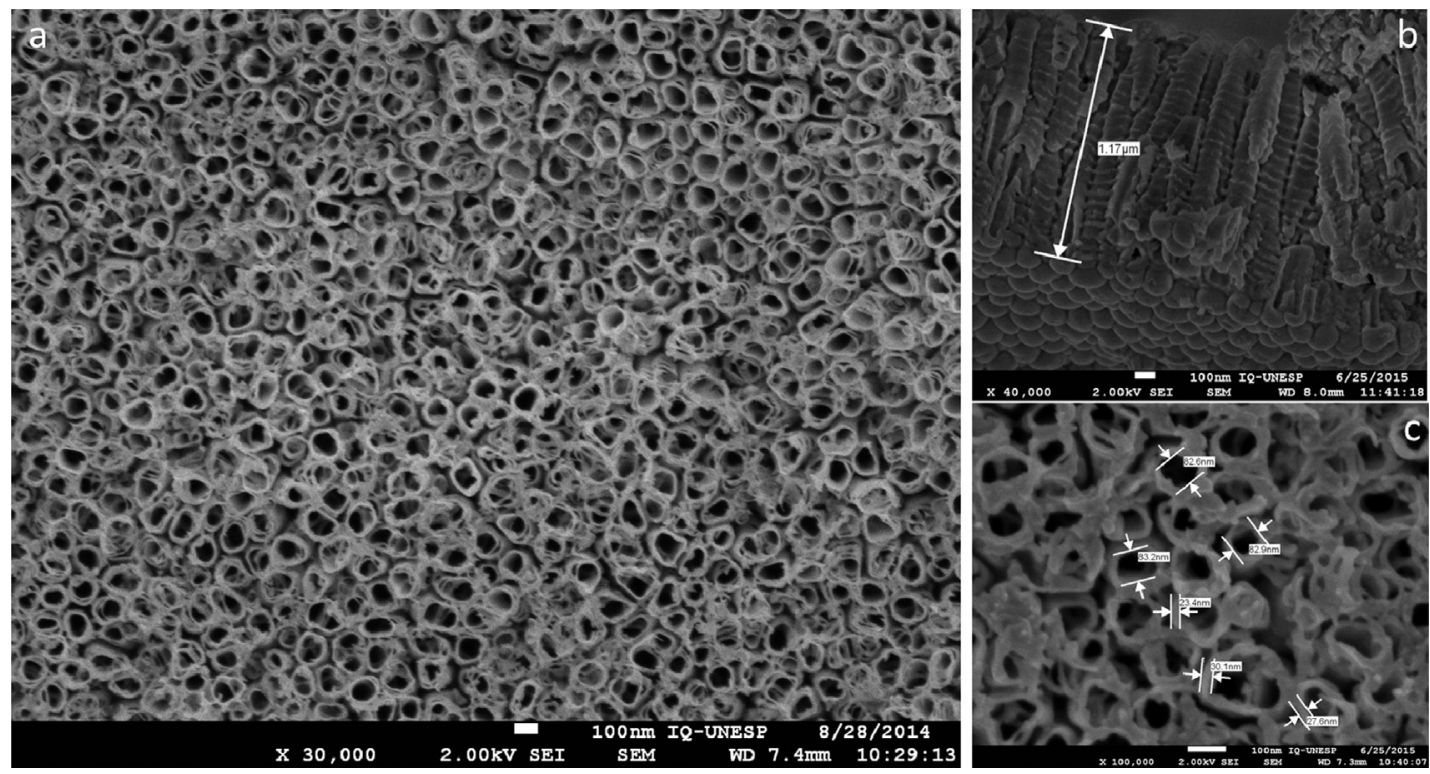

Fig. 1. FE-SEM images from the top of the $\mathrm{Ti} / \mathrm{TiO}_{2}-\mathrm{NT}(\mathrm{A})$ with the wall thickness and diameter presented (B) and a cross section view (C). 
galvanostat (Autolab) controlled by NOVA 2.0 software (metrohm Autolab).

\subsection{Glucose photoelectrocatalytic Oxidation}

Glucose photoelectrooxidation on $\mathrm{Ti} / \mathrm{TiO}_{2}-\mathrm{NT}$ was carried out treating $150 \mathrm{~mL}$ of glucose solution in $0.1 \mathrm{M} \mathrm{Na}_{2} \mathrm{SO}_{4}$ as supporting electrolyte ( $\mathrm{pH}$ 6.60). Samples of the treated solutions were analyzed by ion-exchange chromatography with amperometric detection, total organic carbon (TOC) and gas chromatography with mass spectrometry (GC-MS) techniques.

For the ion exchange chromatographic analysis, samples and standards of glucose, arabinose, gluconic acid and glucaric acid (Sigma Aldrich, >98\%) were analyzed in a liquid chromatograph (850 Professional IC Cation-HP-Gradient), equipped with a Wall-Jet electrochemical cell IC amperometric detector (Au working electrode).The analytes separation was carried out in an analytical ion exchange column Dionex ${ }^{\mathbb{R}} \hat{O}$ CarboPac $^{\mathrm{TM}}$ PA1 $(250 \mathrm{~mm} \times 4.0$ $\mathrm{mm} \times 10 \mu \mathrm{m})$ using a $260 \mathrm{mV}$ potential for detection. With this objective in mind, we applied a gradient method having as mobile phases a mixture of $0.1 \mathrm{M} \mathrm{NaOH}+0.28 \mathrm{M} \mathrm{NaOAc}(\mathrm{A}, 1.0 \mathrm{ml} / \mathrm{min})$, ultrapure water $(B, 1.0 \mathrm{ml} / \mathrm{min}$ ) and $0.3 \mathrm{M} \mathrm{NaOH}$ (C post-column, $0.3 \mathrm{~mL} / \mathrm{min}$ ). The method used was $10 \%$ of A phase from 0 to $3 \mathrm{~min}$, which was then raised to $100 \%$ between 3 to 9 min and kept at $100 \%$ for 6 minutes.

For GC-MS analysis, the samples were lyophilized, dissolved in methanol (J.T. Baker, 99.97\%), filtered in $0.45 \mu \mathrm{m}$ filter while subsequently made to undergo drying. A portion of the dried samples (5-10 mg) was solubilized in $100 \mu \mathrm{L}$ of pyridine and derivatized with $80 \mu \mathrm{L}$ of a $20 \mathrm{mg} / \mathrm{ml}$ pyridine solution of methoxyaminechlorhydrate (Sigma-Aldrich, 98\%). Following
90 minutes of heating $\left(30^{\circ} \mathrm{C}\right)$, the samples were derivatized with $200 \mu \mathrm{L}$ of $N$-methyl-N(trimethylsilyl)trifluoroacetamide (MSTFA) (Sigma-Aldrich, 98,5\%), heating the samples at $37^{\circ} \mathrm{C}$ for 30 minutes, which was in turn followed by cooling at $5{ }^{\circ} \mathrm{C}$ for $24 \mathrm{~h}[34,35]$. Following the derivatizations, the samples were injected in GC-MS(Shimadzu, model QP2010), using a temperature ramp in the range of 100.0 to $300.0^{\circ} \mathrm{C}$ for $70 \mathrm{~min}$. To carry out the separation, an EN5MS capilar column $(30.0 \mathrm{~m} \times 0.25 \mu \mathrm{m} \times 0.25$ $\mathrm{mm}$ ) was used. For mass spectrometry, a $70 \mathrm{eV}$ electronic impact ionization was applied.

The $\mathrm{OH}^{\bullet}$ formation was monitored using the bleaching reaction of $0.05 \mathrm{mM}$ p-nitrosodimethylaniline (RNO) solution (SigmaAldrich, 97\%) through UV-vis spectrophotometry analysis (Agilent, Cary 60) [36-38]. According to Simonsen et al. [38], hydroxyl radicals generation tends to engender the seletive oxidation of RNO which promotes a decrease in the characteristic bands at $440 \mathrm{~nm}$.

\section{Results and discussion}

\subsection{Electrode Characterization}

Fig. 1 shows the characteristic SEM images, for the $\mathrm{Ti} / \mathrm{TiO}_{2}$ nanotube electrodes $\left(\mathrm{Ti} / \mathrm{TiO}_{2}-\mathrm{NT}\right)$. Uniform and homogenous nanotubes overlying the titanium plate surface are seen in the SEM images. These nanotubes presented a wall thickness of 20$30 \mathrm{~nm}$, diameter of $80-90 \mathrm{~nm}$ and an average length of $1.2 \mu \mathrm{m}$.

Fig. 2 presents the XRD spectrum, the energy dispersive spectroscopy X-ray and the absorbance of the material upon light incidence. Material crystallinity was confirmed by XRD spectra (Fig. 2A), where the signals at $2 \theta-25.0$ and 47.8 were found to be
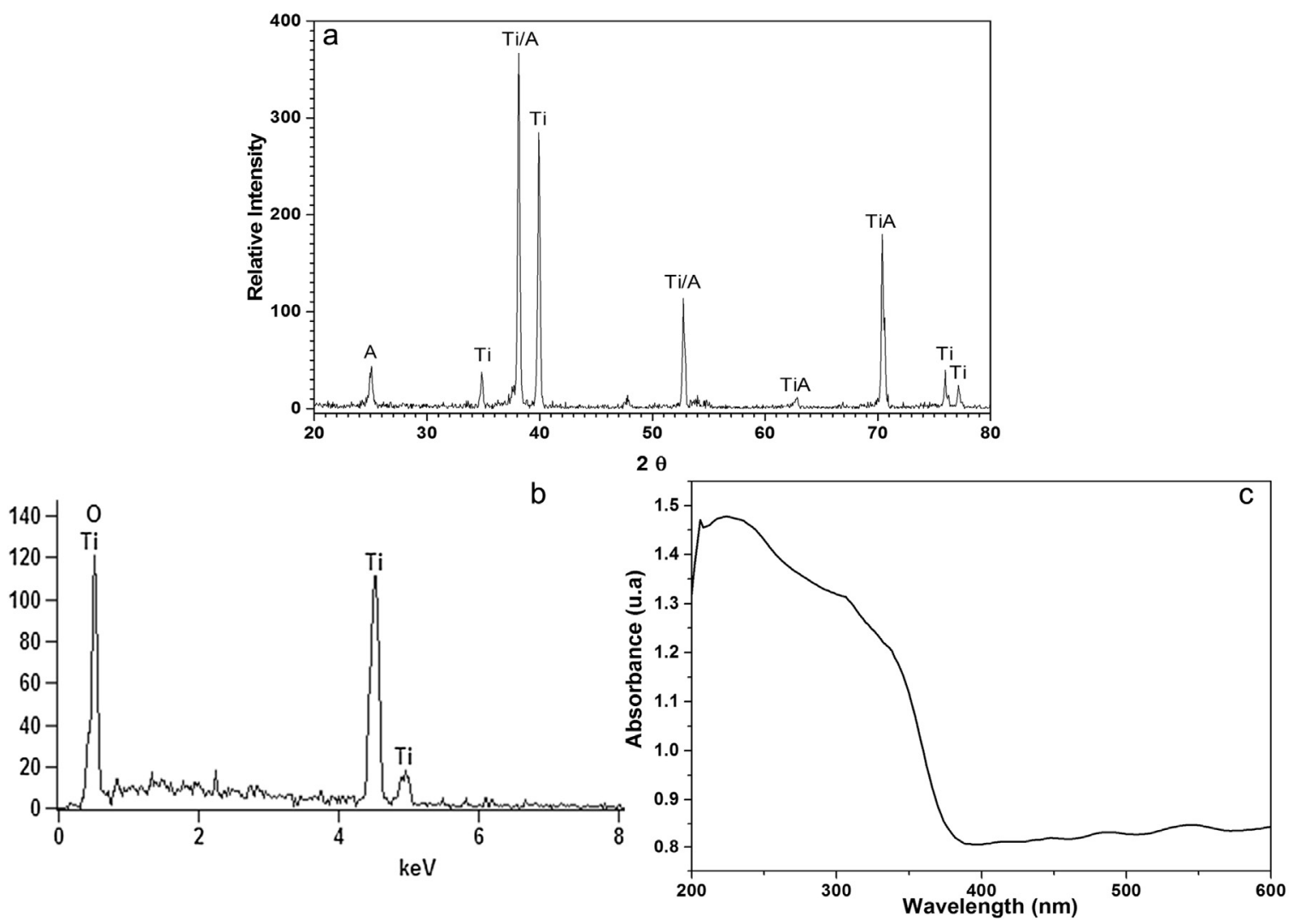

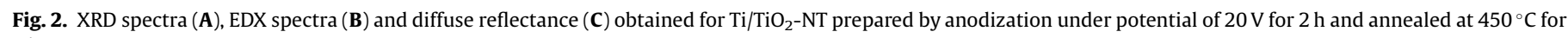
$2 \mathrm{~h}$. 
characteristics of the anatase $\mathrm{TiO}_{2}$ phase $[39,40]$. Energy dispersive spectroscopy X-ray (EDX) analysis confirmed the presence of elements that primarily constitute the $\mathrm{Ti} / \mathrm{TiO}_{2}-\mathrm{NT}$ electrode. The spectrum displayed relatively intense peaks typical of the presence of oxygen and titanium on the material surface, without impurities (Fig. 2B).

The diffuse reflectance analysis is presented in Fig. 2C. The absorbance spectrum of the electrode exhibited a high optical absorption in $\lambda<380 \mathrm{~nm}$ relative to ultraviolet region as expected for $\mathrm{TiO}_{2}$ materials [41]. Tauc's graph $[42,43]$ obtained from $(\alpha \mathrm{h} v)^{1 /}$ ${ }^{2} v s \mathrm{E}(\mathrm{eV}), \alpha=0$, indicated a band gap energy around $3.1 \mathrm{eV}[9]$.

\subsection{Curves of Photocurrent vs potential for glucose oxidation on Ti/ $\mathrm{TiO}_{2}$-NT electrode}

Fig. 3 illustrates photocurrent vs potential curves obtained for $\mathrm{Ti} / \mathrm{TiO}_{2}$-NT electrode in $0.1 \mathrm{M} \mathrm{Na}_{2} \mathrm{SO}_{4}$, in the dark (Curve $\mathrm{A}$ ) and under UV irradiation in the absence (Curve $\mathrm{B}$ ) and presence of glucose at concentrations ranging from 10 to $250 \mathrm{mM}$ (Curves $C$ to F). The electrode in sodium sulfate supporting electrolyte is found to have no measurable current in the dark. However, a well-defined wave is seen raised around $-0.20 \mathrm{~V}$, reaching a maximum value of $4 \mathrm{~mA} \mathrm{~cm}^{-2}$ at potentials higher than $+1.0 \mathrm{~V}$ when irradiated by UV light. It is noteworthy that the aforementioned observation indicates that under light with $\lambda \leq 380 \mathrm{~nm}$, the generation of charges is seen to occur on the electrode $\left(\mathrm{e}^{-} / \mathrm{h}^{+}\right)$. The application of anodic potentials relatively higher than the flat band potentials, in essence, efficiently forces the electrons to pass through the counter electrode, leaving behind them photogenerated holes that tend to react with $\mathrm{H}_{2} \mathrm{O} / \mathrm{OH}^{-}$, giving rise to $\mathrm{OH}^{\bullet}$ radicals [19,44]. Nonetheless, the photocurrent is found to increase in the presence of glucose, reaching a current of around 4 times higher in the presence of $250 \mathrm{mM}$ of glucose (Curve F). This behavior implies that adsorbed glucose molecules can be acting as holes scavenger on the electrode surface, which minimizes the recombination process, yielding higher photocurrents. In addition, Fig. 3 (Curves $C$ to $F$ ) indicates that photocurrent taken at $E=+1.0 \mathrm{~V}$ increased with glucose concentration. It can explain the fact that curves $\mathrm{E}$ and $\mathrm{F}$ (Fig. 3) did not presented a plateau. The higher concentration of the

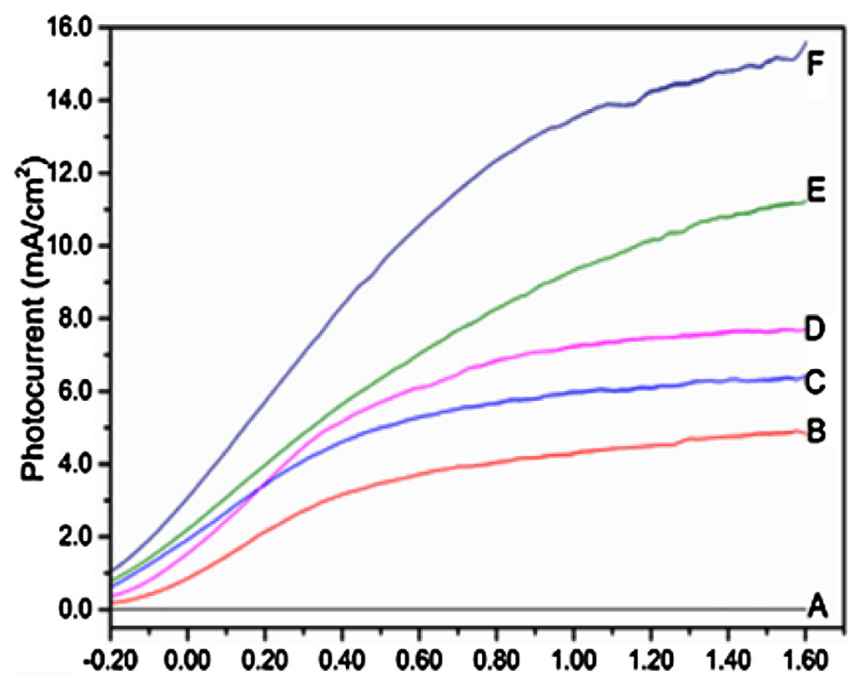

Fig. 3. Linear scan voltammetric curves for $\mathrm{Ti} / \mathrm{TiO}_{2}-\mathrm{NT}$ in $0.1 \mathrm{M} \mathrm{Na}_{2} \mathrm{SO}_{4}$ under dark (Curve A) and UV irradiation in the absence (Curve B) and presence of glucose concentrations: $10 \mathrm{mM}$ (C); $50 \mathrm{mM}$ (D); $100 \mathrm{mM}$ (E); $250 \mathrm{mM}$ (F). $\nu=10 \mathrm{mV} \mathrm{s}^{-1} . \mathrm{pH}$ 6.60 . glucose in solution contributes towards intensifying the separation of $\mathrm{e}^{-} / \mathrm{h}^{+}$and making difficult a stabilization of the photocurrent.

The results indicate that glucose is probably contributing towards intensifying the separation of $\mathrm{e}^{-} / \mathrm{h}^{+}$on the $\mathrm{Ti} / \mathrm{TiO}_{2^{-}}$ NTelectrodes as an efficient hole trapper. This behavior leads to believe that glucose can be oxidized directly by the photogenerated $\mathrm{h}^{+}$on the electrode surface [32] and not by the preponderant hydroxyl radicals $\left(\mathrm{OH}^{\bullet}\right)$ emanating from the water oxidation. This hypothesis can be said to be remarkably relevant to the process given that glucose oxidation aiming at converting it into other products is, in effect, competing with the simultaneous process involving the degradation of glucose by hydroxyl radicals (potent oxidant).

In an attempt to prove this hypothesis, the $\mathrm{OH}^{\bullet}$ production was monitored during $15 \mathrm{~min}$ of photoelectrocatalytic oxidation on Ti/ $\mathrm{TiO}_{2}$-NTusing a $0.05 \mathrm{mM}$ RNO solution, in the absence and presence of $10.0 \mathrm{mM}$ glucose by UV-vis spectrophotometry analysis, as described in item 2.4. The reaction of RNO with $\mathrm{OH}^{*}$ has a constant rate of $1.25 \times 10^{10} \mathrm{M}^{-1} \mathrm{~s}^{-1}$ [38], ensuring that de $\mathrm{OH}^{\bullet}$ will react preferentially with RNO molecules and/or with glucose in solution. The results are shown in Fig. 4. The method is based on the bleaching reaction of RNO (oxidation of p-nitrosodimethylaniline) absorbance at $440 \mathrm{~nm}$ related to the $\mathrm{OH} \bullet$ formation, using the relationship:- $\ln [R N O] /[R N O]_{0}=k_{\exp } t$, where $\mathrm{k}_{\mathrm{exp}}=\mathrm{k}[\mathrm{OH} \bullet]_{\mathrm{ss}}, \quad[\mathrm{RNO}]=$ concentration of $\mathrm{RNO},[\mathrm{RNO}]_{0}=$ initial concentration of $\mathrm{RNO},[\mathrm{OH} \bullet]_{\mathrm{ss}}=$ steady state concentration of $\mathrm{OH} \bullet, \mathrm{t}=$ time of reaction and $\mathrm{k}=1.25 \times 10^{10} \mathrm{M}^{-1} \mathrm{~s}^{-1}$ [36]. The slope of the semi-log plot indicates the production rate of the steady state of $\mathrm{OH} \bullet[36]$, which are $-9.65 \times 10^{-4}$ and $-2.88 \times 10^{-4}$ when photoelectrocatalysis is carried out on $\mathrm{Ti} / \mathrm{TiO}_{2}-\mathrm{NT}$ in sodium sulfate without (A) and with (B) $10.0 \mathrm{mM}$ glucose. By the equation, following $15 \mathrm{~min}$ of treatment, the steady state concentration of $\mathrm{OH}^{\bullet}$ are $8.50 \times 10^{-14} \mathrm{mM}$ and $2.65 \times 10^{-14} \mathrm{mM}$ respectively. Thus, it is clear that the generation of $\mathrm{OH}^{\bullet}$ is suppressed in the presence of glucose, suggesting that the competitive water oxidation observed owing to the photogenerated holes is minimized on the electrode surface when glucose is adsorbed preferentially [45], butthere is a possibility that glucose could be consuming by $\mathrm{OH} \bullet$ radicals more rapidly than with RNO.

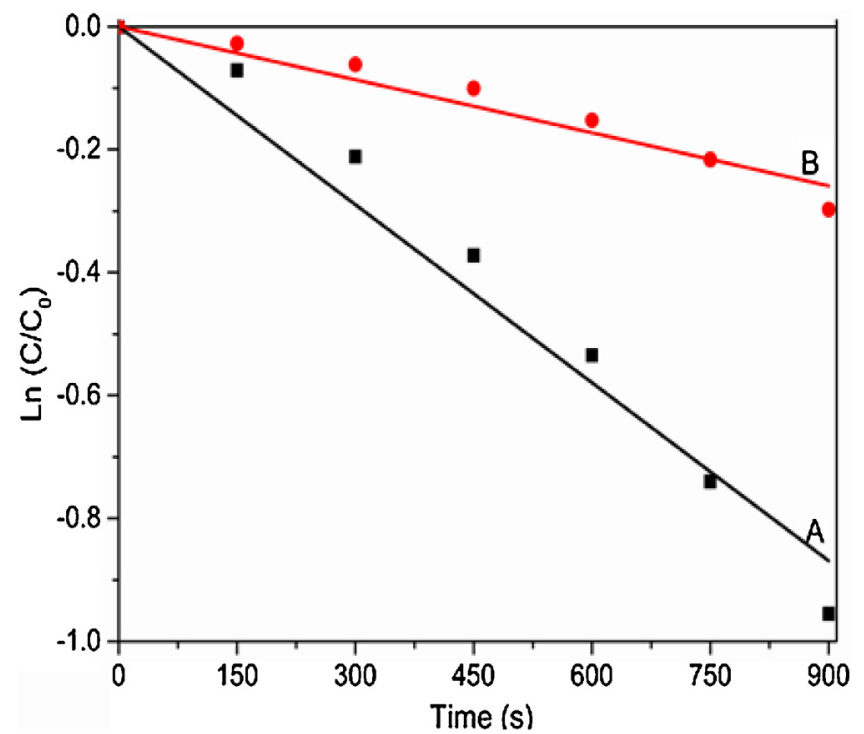

Fig. 4. Effect of glucose on the production rate of the hydroxyl radical steady state (measured by RNO method) during 900 seconds of photoelectrocatalysis conducted on $\mathrm{Ti} / \mathrm{TiO}_{2}-\mathrm{NT}, \mathrm{E}_{\mathrm{app}}=+1.5 \mathrm{~V}+\mathrm{UV}$ irradiation in $0.1 \mathrm{M} \mathrm{Na}_{2} \mathrm{SO}_{4}$ without $(\mathbf{A})$ and with $10 \mathrm{mM}$ glucose $(\mathbf{B})$ 

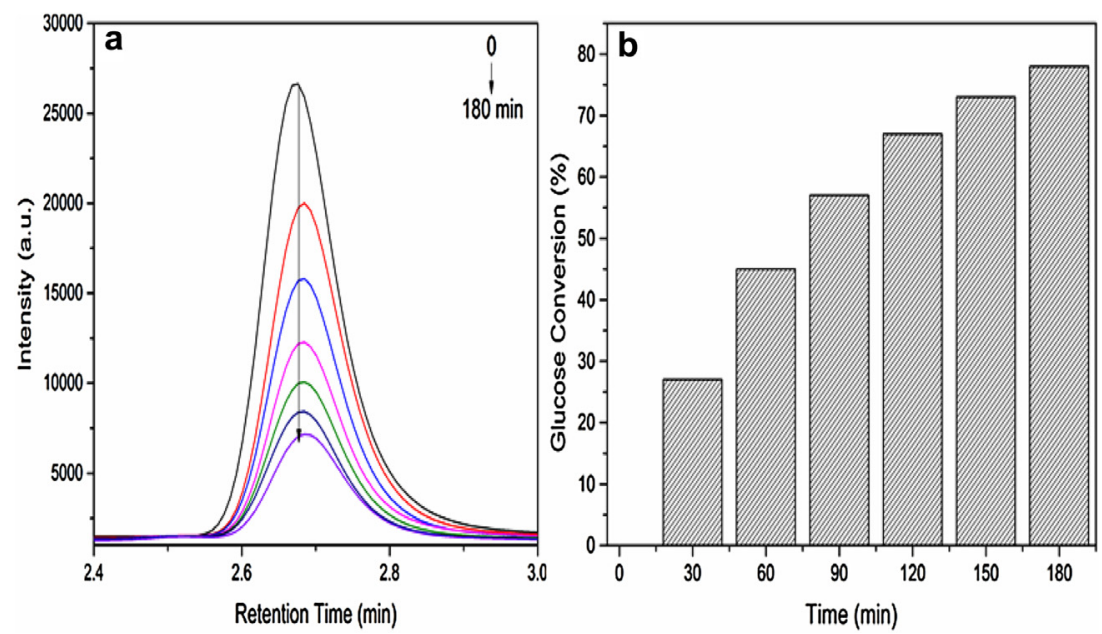

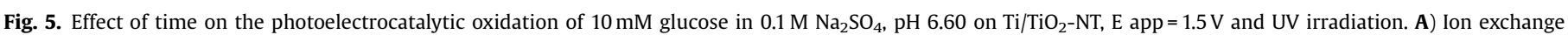
chromatograms for glucose in solution during 0 to $180 \mathrm{~min}$ treatment. B) Graphs of \% glucose conversion during the treatment.

\subsection{Glucose photoelectrocatalytic oxidation}

Fig. 5 illustrates the conversion of $10.0 \mathrm{mM}$ of glucose in $0.1 \mathrm{M}$ $\mathrm{Na}_{2} \mathrm{SO}_{4}$ during 180 min of photoelectrocatalytic treatment on $\mathrm{Ti} /$ $\mathrm{TiO}_{2}$-NT operating at $\mathrm{E}_{\mathrm{app}}=+1.5 \mathrm{~V}$ and UV irradiation. The glucose oxidation was monitored by ionic chromatography with amperometric detector at retention time of $2.65 \mathrm{~min}$, as shown in curve $\mathrm{A}$ of Fig. 5, where a decrease is seen in the peak area as a function of treatment time. Calibration curves were constructed from 0.1 to $1.0 \mathrm{mM}$ of standard glucose solution by ion-exchange chomatography with amperometric detection, following the equation: Area (a.u.) $=8486$ [glucose] $(\mathrm{mM}), \mathrm{r}^{2}=0.9979$. The detection limit calculated via the analytical curve method was $0.056 \mathrm{mM}$, the solutions were diluted by $1: 10$ ratio before all the chromatographic analysis. Fig. 5B shows that glucose conversion is increased during the treatment time reaching maximum values following 180 minutes of treatment, where $78 \%$ of glucose conversion is found to be reached.

Aiming at optimizing the method, $10.0 \mathrm{mM}$ glucose in $0.1 \mathrm{M}$ $\mathrm{Na}_{2} \mathrm{SO}_{4}$ was subjected to 30 min of photoelectrocatalytic treatment on $\mathrm{Ti} / \mathrm{TiO}_{2}-\mathrm{NT}$ operating at UV irradiation, where varying degrees of pontentials were tested $(0.2-1.5 \mathrm{~V})$ and $\mathrm{pH}$ solution from 2.0 to 10.0. During this experiment, the constant potential apllied was kept at $1.0 \mathrm{~V}$, but taking into acount that the potential values could be changed according to the equation $0.0591 \mathrm{~V}$ per $\mathrm{pH}$ unit, these values were corrected. As shown in Table 1 the potentials varied from $1.1 \mathrm{~V}$ in $\mathrm{pH} 2.0$ to $1.6 \mathrm{~V}$ in $\mathrm{pH} 10.0$. These potentials

\section{Table 1}

Effect of $\mathrm{pH}$ and applied potential on the glucose removal following $30 \mathrm{~min}$ of photoelectrocatalytic oxidation of $150 \mathrm{~mL}$ glucose $10 \mathrm{~m} \mathrm{~mol} \mathrm{~L}^{-1}$ in $0.1 \mathrm{~mol} \mathrm{~L}^{-1}$ $\mathrm{Na}_{2} \mathrm{SO}_{4}$ on $\mathrm{Ti} / \mathrm{TiO}{ }_{2}$-NT.

\begin{tabular}{lllll}
\hline \multicolumn{2}{l}{ Influence of $\mathrm{pH}^{\mathrm{a}}$} & & \multicolumn{2}{l}{ Influence of Potential $^{\mathrm{b}}$} \\
\cline { 1 - 1 } $\mathbf{2 . 0}$ & Glucose Convertion (\%) & & Potential (V vs ECS) & Glucose Convertion (\%) \\
\hline $\mathbf{4 . 0}$ & 22.4 & $\mathbf{0 . 2}$ & $\mathbf{0 . 4}$ & 15.2 \\
$\mathbf{6 . 0}$ & 23.9 & $\mathbf{0 . 6}$ & 18.3 \\
$\mathbf{8 . 0}$ & 24.2 & $\mathbf{0 . 8}$ & 23.3 \\
$\mathbf{1 0 . 0}$ & 22.2 & $\mathbf{1 . 0}$ & 23.7 \\
& & $\mathbf{1 . 5}$ & 24.2 \\
\hline
\end{tabular}

\footnotetext{
a $10.0 \mathrm{mM}$ Glucose; $0.1 \mathrm{Na}_{2} \mathrm{SO}_{4} ; \mathrm{E}=1.0 \mathrm{~V}$ (vs ECS) (+0.0591 V per pH unit).
}

b $10.0 \mathrm{mM}$ Glucose; $0.1 \mathrm{Na}_{2} \mathrm{SO}_{4} ; \mathrm{pH} 6.60$. corresponded to the plateau region of photocurrent vs potential region. Best performance was obtained at $6<\mathrm{pH}<8$, where glucose favored adsorption. According to literature [46], in acidic $\mathrm{pH}$ glucose in solution are mainly in molecular form, bonding to $\mathrm{TiO}_{2}$ surface through its $\mathrm{O}$ hydroxil while the $\mathrm{TiO}_{2}$ surface has a positive charge taking into account the isoeletric point of $\mathrm{TiO}_{2}$ which is around 5.3 [44]. In pH 6.0-8.0, will make the adsorbed glucose to dissociate into $\mathrm{H}^{+}$and $\mathrm{RCH}_{2}-\mathrm{O}^{-}$, becoming a better hole trapper than the molecular form, resulting in a enhancement in the activity. Furthermore, the optimum potential is found to be at $1.0<\mathrm{E}_{\mathrm{app}}<1.5 \mathrm{~V}$, since these potentials presented the higher conversion of glucose percetage (Table 1). Accordingly, further studies were conducted using the electrolyte $0.1 \mathrm{M} \mathrm{Na}_{2} \mathrm{SO}_{4}$ without $\mathrm{pH}$ correction ( $\mathrm{pH} 6.60)$ and with an applied potential of $1.5 \mathrm{~V}$.

The influence exerted by the initial concentration of glucose on the performance of $\mathrm{Ti} / \mathrm{TiO}_{2}$ was investigated for 5.00, 10.0, 25.0, $50.0,100$ and $250 \mathrm{mM}$ of glucose in $0.1 \mathrm{M} \mathrm{Na}_{2} \mathrm{SO}_{4}$. The

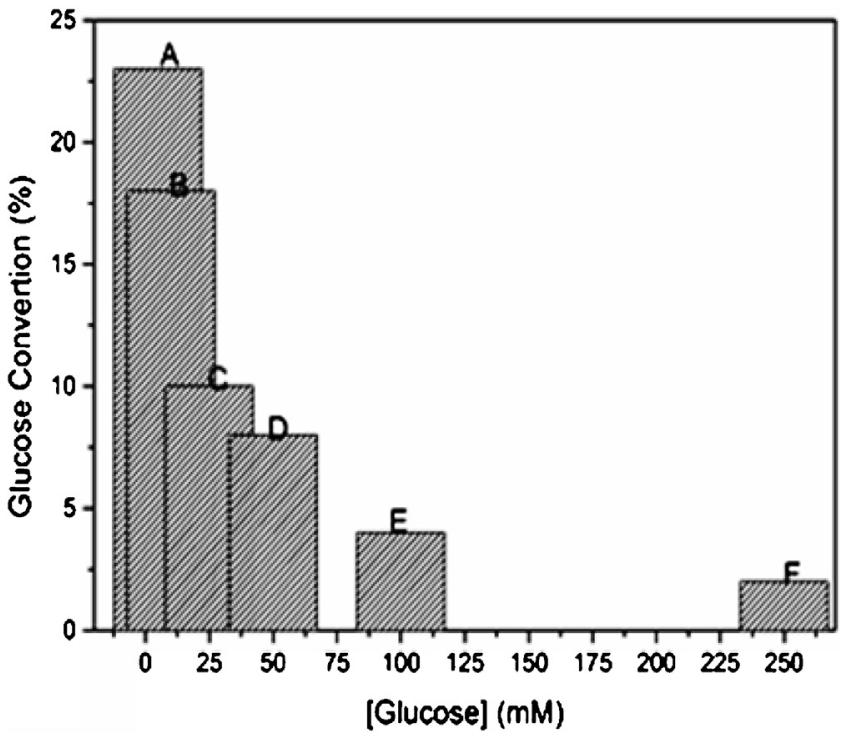

Fig. 6. Oxidation of Glucose following $30 \mathrm{~min}$ of photoelectrocatalysis conducted on $\mathrm{Ti} / \mathrm{TiO}_{2}$-NT electrode for: A) $5 \mathrm{mM}$; B) $10 \mathrm{mM}$ C) $25 \mathrm{mM}$, D) $50 \mathrm{mM}$, E) $100 \mathrm{mM}, \mathrm{F}$ ) $250 \mathrm{mM}$ in $0.1 \mathrm{M} \mathrm{Na}_{2} \mathrm{SO}_{4}$ in $\mathrm{pH} 6.60 \mathrm{E}=+1.5 \mathrm{~V}$ and $\mathrm{UV}$ irradiation. 

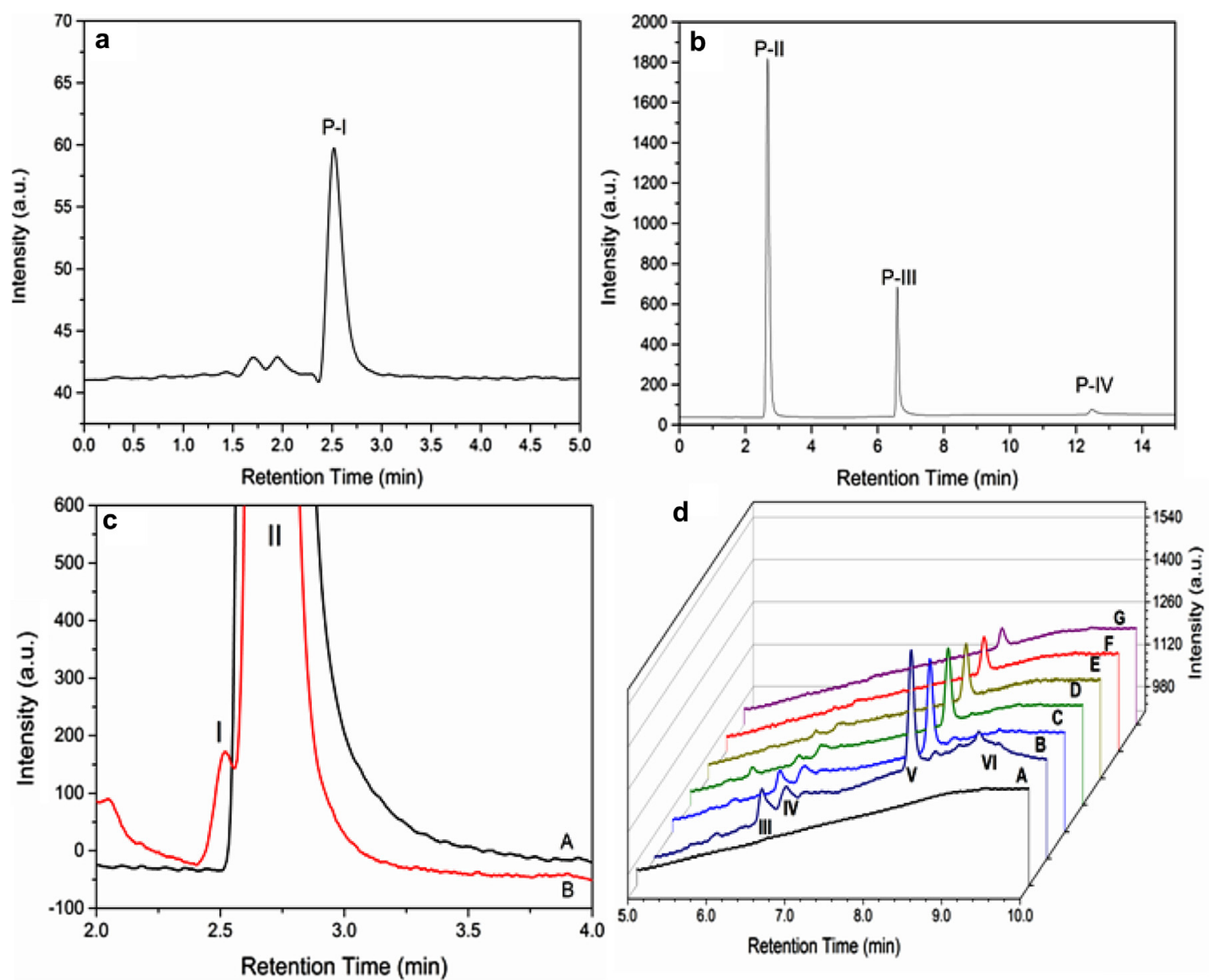

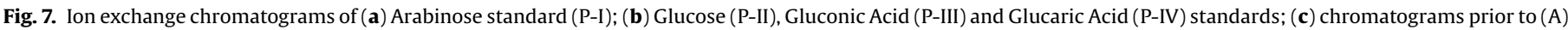

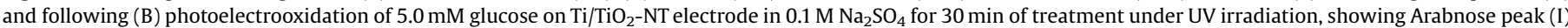

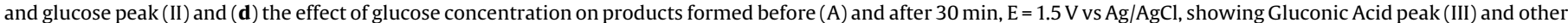
unindentified products (IV to VI). Glucose: $5.0 \mathrm{mM}(\mathrm{B}), 10.0 \mathrm{mM}(\mathrm{C}), 25.0 \mathrm{mM}(\mathrm{D}), 50.0 \mathrm{mM}(\mathrm{E}), 100.0 \mathrm{mM}(\mathrm{F}) \mathrm{and} 250.0 \mathrm{mM}(\mathrm{G})$ in pH 6.60.

photoelectrocatalysis was carried out at $+1.5 \mathrm{~V}$ and $\mathrm{UV} / \mathrm{Vis}$ irradiation. The percentage conversion of glucose after $30 \mathrm{~min}$ of treatment is shown in Fig. 6. The results show that higher conversion percentages are achieved at lower concentrations of glucose. This behavior suggests that the reaction is dependent on the glucose concentration on the catalyst surface. At higher values, the electrode surface will be saturated due the gradual adsorption of glucose, implying in a lower catalytic efficiency. By this, it is believed that the process might be controlled by glucose adsportion on the electrode surface [47]. Thus, further measurements were performed for glucose at $10.0 \mathrm{mM}$.

\subsection{Analysis of products generated during photoelectrocatalytic oxidation of glucose}

Fig. 7 illustrates characteristic ion exchange chromatograms obtained for standards of Arabinose (P-I) (Curve A); Glucose (P-II), Gluconic acid (P-III) and Glucaric acid (P-IV) (Curve B) and the chromatograms after $30 \mathrm{~min}$ of photoelectrolysis of glucose at concentrations ranging from $5.0-250 \mathrm{mM}$, at $\mathrm{E}=+1.5 \mathrm{~V}$, UV irradiation (Curves C and D). In Fig. 7 (curve C), it is possile to indentify Arabinose as peak I ( RT = $2.50 \mathrm{~min}$ ) and glucose as peak II $(\mathrm{RT}=2.67 \mathrm{~min})$ through comparison with the standards. All the chromatograms obtained (Curve D) exhibited a peak at RT $=8.5$ min (peak III) which is found to be present at any of the glucose concentrations following $30 \mathrm{~min}$ of treatment. The peak is found to be more intense when lower concentrations of glucose is photoelectrolyzed. By comparison with the standard solution of glucose, gluconic acid and glucaric acid (Curve B) which in the same experimental conditions exhibited well defined peaks at retention times of $2.67 \mathrm{~min}, 6.60 \mathrm{~min}$ and $12.47 \mathrm{~min}$ (not shown), peak IV at $6.60 \mathrm{~min}$ could be attributed to gluconic acid, the other peaks were, however, left unidentified.

Using the best optimized conditions, Fig. 8 illustrates glucose conversion obtained following $180 \mathrm{~min}$ of photoelectrocatalytic treatment conducted in sodium sulfate under $\mathrm{pH} 6.6$ at $\mathrm{E}=1.5 \mathrm{~V}+$ UV irradiation and the total organic carbon removal (Curve $\mathbf{A}$ ). For the conversion of $78 \%$ of glucose after 180 min of treatment (Curve A), the total organic carbon is found to be almost constant during the first $30 \mathrm{~min}$, but then decays during longer times, reaching a maximum of $28 \%$ of TOC removal. These results point out that despite the fact that a greater proportion of glucose was oxidized, only $28 \%$ was, in effect, mineralized to $\mathrm{CO}_{2}$ and $\mathrm{H}_{2} \mathrm{O}$. A glucose conversion of $78 \%$ in $3 \mathrm{~h}$ of reaction is a memorable value, higher than others values obtained for exemple by Zhang and coworkers [28] that obtained $66 \%$ of glucose conversion using $\mathrm{TiO}_{2}$ nanotube photonic crystal after $6 \mathrm{~h}$ of photoelectrocatalysis. Probably, in a higher time of reaction, more percentage of glucose could be converted, despite the possibility of mineralization.

The ion exchange chromatograms for products generated withretention times between 2.0 to $4.0 \mathrm{~min}$ are shown in Fig. 8 , Curve B for solutions prior to (A) and following (B) 180 minutes of 

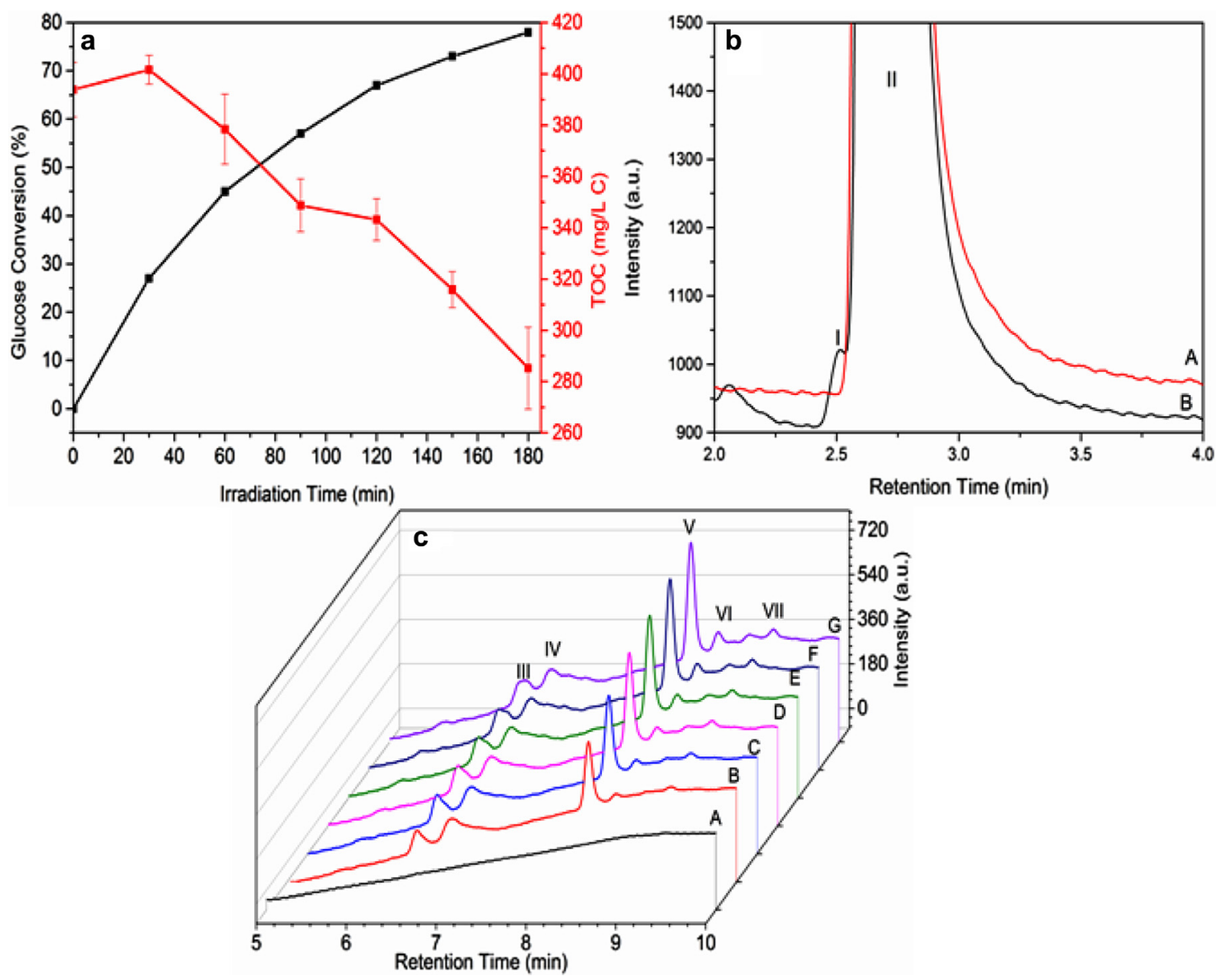

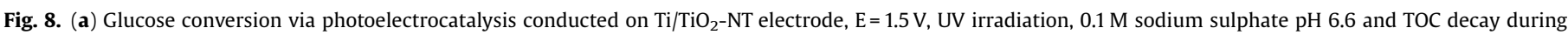

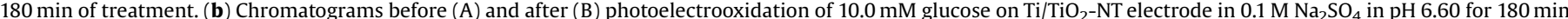

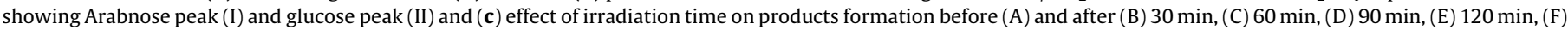
$150 \mathrm{~min}$ and (G) $180 \mathrm{~min}$ of treatment under UV irradiation, showing Gluconic Acid peak (III) and other unindentified products (IV to VII).

treatment. A further observation worth mentioning is the peaks seen at retention times of $2.50 \mathrm{~min}$ (arabinose) and $2.67 \mathrm{~min}$ (glucose) identified through comparison with the standard solution. Through the enlarged chromatograms of retention times between 5.0 to $10.0 \mathrm{~min}$ (Curve $\mathbf{C}$ ), prior to (A) and following 30180 min $(B-G)$ of treatment, one can detect at least 5 peaks, among which peak IV (RT $=6.60 \mathrm{~min})$ can be attributed to gluconic acid. The other peaks have not been indentified.

The analysis of the chromatograms indicates that gluconic acid is, as clearly observed, a product generated during all the process, which is found to increase with anincrease in the photoelectrocatalysis time. In addition, the results also show that glucose is
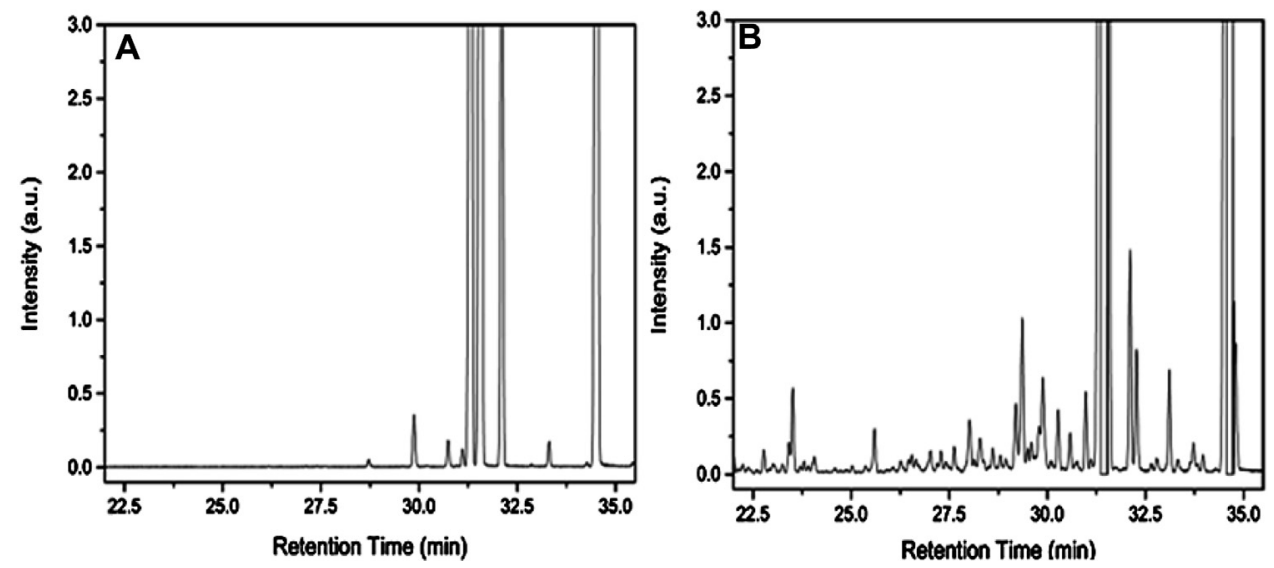

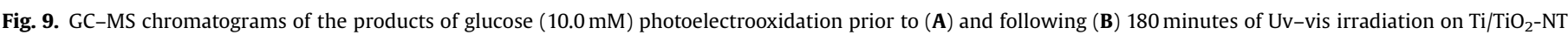
electrodes in $\mathrm{Na}_{2} \mathrm{SO}_{4} 0.1 \mathrm{M}$ under potential of $1.5 \mathrm{~V}$ vs $\mathrm{Ag} / \mathrm{AgCl}$, after derivatization reactions (experimental section). 
Table 2

Products from glucose $(10.0 \mathrm{mM})$ photoelectrooxidation following $180 \mathrm{~min}$ of $\mathrm{Uv}$ vis irradiation on $\mathrm{Ti} / \mathrm{TiO}_{2}-\mathrm{NT}$ electrodes with $0.1 \mathrm{M} \mathrm{Na}_{2} \mathrm{SO}_{4}$ in $\mathrm{pH} 6.60$ under potential of $1.5 \mathrm{~V}$ vs $\mathrm{Ag} / \mathrm{AgCl}$ identified by GC-MS analysis and their respective retention time.

\begin{tabular}{lll}
\hline Products & Retention Time (minutes) & Similarity (\%) \\
\hline Arabinose & 22.7 & 89 \\
Arabitol & 25.6 & 86 \\
4-ketoglucose & 29.2 & 84 \\
Gluco-dialdose & 29.3 & 93 \\
Glucone- $\delta$-lactone & 31.0 & 87 \\
6-deoxyglucose & 33.1 & 87 \\
Gluconic Acid & 34.8 & 93 \\
\hline
\end{tabular}

converted through photoelectrochemical oxidation, an outcome which confirms that perhaps glucose is oxidized by photogenerated holes [32] and not by hydroxyl radicals, which could amplify its degradation to $\mathrm{CO}_{2}$.

As discussed previously, the literature [13-17] reports the formation of gluconic acid, glucaric acid, arabinose, erytrose and arabitol as the main products of glucose during photocatalytic oxidation. In this study, the only products identified were arabitol, arabinose and gluconic acid, suggesting that the applied potential is not only operating with the purpose of separating charges in the photoelectrocatalytic system, but it may also be acting aiming at interfering in the products formed.

In order to identify the most of the products that were not possible to be recognized by ionic chromatography, the sample treated for $180 \mathrm{~min}(\mathrm{t}=180 \mathrm{~min})$ along with the original sample without treatment $(\mathrm{t}=0 \mathrm{~min})$ were analysed by GC-MS, as described in the experimental section. Fig. 9 compares the total chromatogram obtained by GC-MS analysis for the samples at initial photoelectrocatalysis (T-0) (Curve A) and following $180 \mathrm{~min}$ of treatment (T-180) (Curve B). It can be observed that many substances formed after $180 \mathrm{~min}$ of photoelectrochemical treatment are not detectable in the origial sample.

Comparing the mass spectra obtained for each peak in GC-MS chromatograms with a data library (NIST8 and WILEY228), it is possible to identify at least seven main substances listed in Table 2 with their respective retention time and similarity to data library. The main peak refers to gluconic acid as identified by ion exchange chromatography.

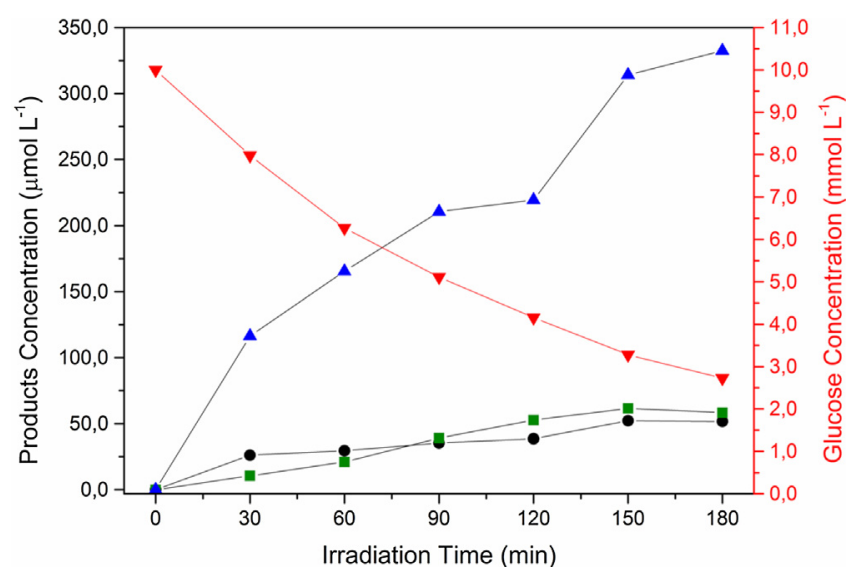

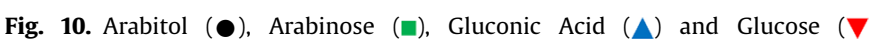
concentrations, during 180 minutes of Uv-Vis irradiation of a $10.0 \mathrm{mM}$ glucose solution, on Ti/TiO $-\mathrm{NT}$ electrodes in $\mathrm{Na}_{2} \mathrm{SO}_{4} 0.1 \mathrm{M}$ under potential of $1.5 \mathrm{~V}$ vs $\mathrm{Ag}$ / $\mathrm{AgCl}$ in $\mathrm{pH} 6.60$.

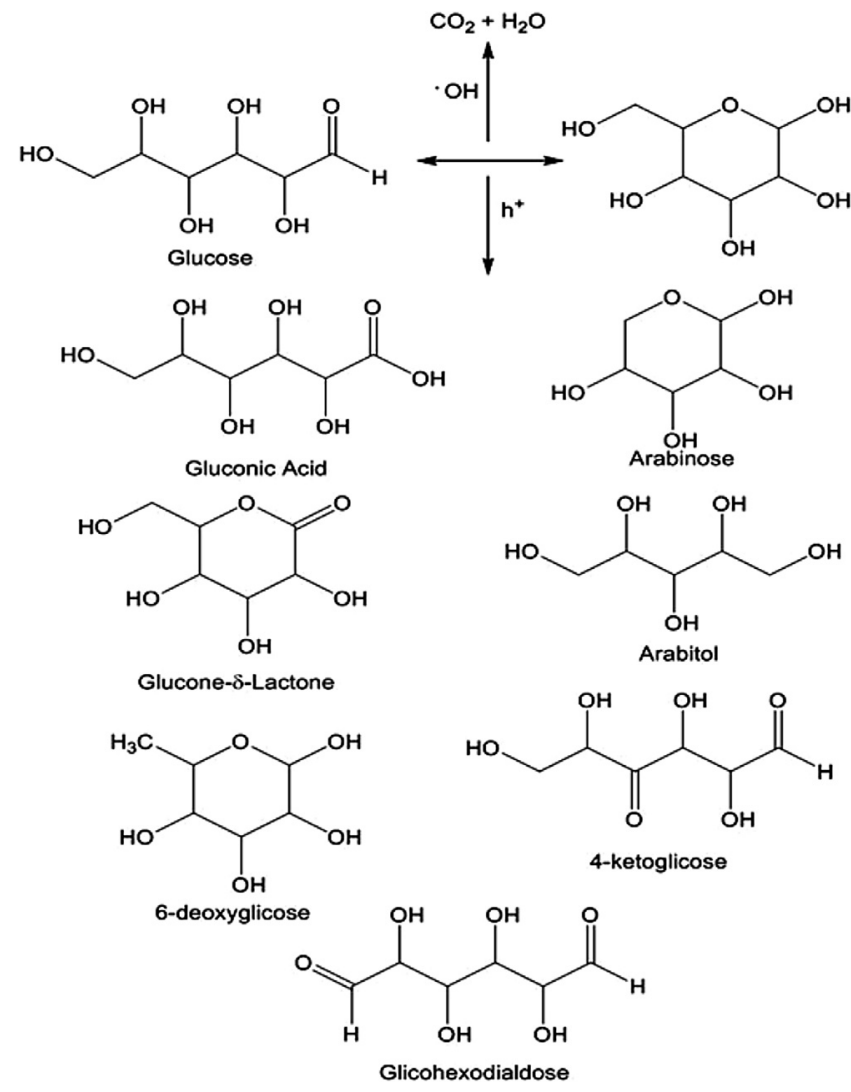

Scheme 1. Representative route of oxidation forglucose photoelectrocatalytic oxidation on $\mathrm{Ti} / \mathrm{TiO}_{2}-\mathrm{NT}$ electrode, under $\mathrm{UV}$ irradiation + applied potential of $+1.5 \mathrm{~V}$.

Standards of the seven main substances indentified by CG-MS were further analyzed by ion exchange chromatography and it was possible to quantify Arabitol, Arabinose and Gluconic acid by ionic exchange chromatographic analysis. As shown Fig. 10, glucose sample was submitted to photoelectrocatalytic oxidation during 180 min using UV-vis irradiation and applied potential of $1.5 \mathrm{~V}$, and the results indicated a decrease of glucose $(\nabla)$ from $10.0 \mathrm{mM}$ to $2.8 \mathrm{mM}$, while there were formation of Gluconic Acid ( $\Delta)$ in concentration of $340.0 \mu \mathrm{M}$, Arabinose ( $\square$ ) and Arabitol $(\bullet)$ in concentrations arround $50.0 \mu \mathrm{M}$.

Based on this proposal, the possible routes towards the formation of the main products for glucose photoelectron oxidation are represented in Scheme 1. The results indicate that the synergic effect of light and applied potential can promote almost $80 \%$ of glucose conversion at lower concentration. The generation of gluconic acid $(340.0 \mu \mathrm{M})$, arabitol $(50.0 \mu \mathrm{M})$, Arabinose $(50.0 \mu \mathrm{M})$ and other added-value compounds have been clearly proven, while only $28 \%$ of the glucose is found to be converted into $\mathrm{CO}_{2}$ + water.

\section{Conclusions}

The results presented in this study indicate that the heterogeneous photoelectrocatalysis technique using $\mathrm{Ti} / \mathrm{TiO}_{2}-\mathrm{NT}$ electrode may be an important tool when it comes to glucose oxidation in aqueous medium aiming at the formation of added-value chemicals. Although the results are preliminary, it is possible to conclude that the oxidation occurs directly through the photogenerated holes on the semiconductor surface and not via hydroxyl groups. Furthermore, through our experiments we were able to reach $78 \%$ of glucose conversion following $180 \mathrm{~min}$ of UV 
irradiation, under potential of $1.5 \mathrm{~V}$, enabling the identification of seven main substances by GC-MS. It is noteworthy that the glucose photoelectrocatalytic oxidation using the $\mathrm{Ti} / \mathrm{TiO}_{2}-\mathrm{NT}$ electrode process renders possible the formation of these many different substances due the quite similar structure of the new molecules with glucose structure.

\section{Acknowledgments}

The authours would like to express their sincerest gratitude and indebtedness to the Brazilian research funding agencies FAPESP (2008/10449-7 and 2015/18109-4), CAPES and CNPq for the financial support granted in the course of the research.

\section{References}

[1] A.G. Costa, G.C. Pinheiro, F.G.C. Pinheiro, A.B. Dos Santos, S.T. Santaella, R.C. Leitão, The use of thermochemical pretreatments to improve the anaerobic biodegradability and biochemical methane potential of the sugarcane bagasse, Chem. Eng. J. 248 (2014) 363-372, doi:http://dx.doi.org/10.1016/j. cej.2014.03.060

[2] M.M. Aguiar, L.F.R. Ferreira, R.R.T. Monteiro, Use of Vinasse and Sugarcane Bagasse for the Production of Enzymes by Lignocellulolytic Fungi, Brazilian Arch. Biol. Technol. 53 (2010) 1245-1254.

[3] T. Werpy, G. Petersen, Top Value Added Chemicals from Biomass. Volume I Results of Screening for Potential Candidates from Sugars and Synthesis Gas, U. S. Department of Energy, 2004, doi:http://dx.doi.org/10.2172/926125.

[4] P. Gallezot, Conversion of biomass to selected chemical products, Chem. Soc. Rev. 41 (2012) 1538-1558, doi:http://dx.doi.org/10.1039/c1cs15147a.

[5] S. Rapagna, N. Jand, P.U. Foscolo, Catalytic gasification of biomass to produce hydrogen rich gas, Int. J. Hydrogen Energy 23 (1998) 551-557, doi:http://dx. doi.org/10.1016/S0360-3199(97)00108-0.

[6] W. Iwasaki, A consideration of the economic efficiency of hydrogen production from biomass, Int. J. Hydrogen Energy 28 (2003) 939-944, doi:http://dx.doi. org/10.1016/S0360-3199(02)00193-3.

[7] S. Li, S. Xu, S. Liu, C. Yang, Q. Lu, Fast pyrolysis of biomass in free-fall reactor for hydrogen-rich gas, Fuel Process. Technol. 85 (2004) 1201-1211, doi:http://dx. doi.org/10.1016/j.fuproc.2003.11.043.

[8] M. Watanabe, Y. Aizawa, T. Iida, T.M. Aida, C. Levy, K. Sue, et al., Glucose reactions with acid and base catalysts in hot compressed water at $473 \mathrm{~K}$, Carbohydr. Res. 340 (2005) 1925-1930, doi:http://dx.doi.org/10.1016/j. carres.2005.06.017.

[9] J.C. Colmenares, R. Luque, J.M. Campelo, F. Colmenares, Z. Karpiński, A.A. Romero, Nanostructured Photocatalysts and Their Applications in the Photocatalytic Transformation of Lignocellulosic Biomass: An Overview Materials (Basel) 2 (2009) 2228-2258, doi:http://dx.doi.org/10.3390/ ma2042228.

[10] A. Chareonlimkun, V. Champreda, A. Shotipruk, N. Laosiripojana, Catalytic conversion of sugarcane bagasse, rice husk and corncob in the presence of $\mathrm{TiO} 2, \mathrm{ZrO} 2$ and mixed-oxide TiO2-ZrO2 under hot compressed water (HCW) condition, Bioresour. Technol. 101 (2010) 4179-4186, doi:http://dx.doi.org 10.1016/j.biortech.2010.01.037.

[11] C.S. Goh, K.T. Lee, S. Bhatia, Hot compressed water pretreatment of oil palm fronds to enhance glucose recovery for production of second generation bioethanol, Bioresour. Technol. 101 (2010) 7362-7367, doi:http://dx.doi.org/ 10.1016/j.biortech.2010.04.048.

[12] S.J. Lu, S.B. Ji, J.C. Liu, H. Li, W.S. Li, Photoelectrocatalytic oxidation of glucose at a ruthenium complex modified titanium dioxide electrode promoted by uric acid and ascorbic acid for photoelectrochemical fuel cells, J. Power Sources 273 (2015) 142-148, doi:http://dx.doi.org/10.1016/j.jpowsour.2014.09.060.

[13] R.L. Desai, J.A. Shields, Photochemical degradation of cellulose material, Die Makromol. Chemie. 122 (1969) 134-144.

[14] D. Bin, H. Wang, J. Li, H. Wang, Z. Yin, J. Kang, et al., Controllable oxidation of glucose to gluconic acid and glucaric acid using an electrocatalytic reactor, Electrochim. Acta 130 (2014) 170-178, doi:http://dx.doi.org/10.1016/j. electacta.2014.02.128

[15] J.C. Colmenares, A. Magdziarz, A. Bielejewska, High-value chemicals obtained from selective photo-oxidation of glucose in the presence of nanostructure titanium photocatalysts, Bioresour. Technol. 102 (2011) 11254-11257, doi: http://dx.doi.org/10.1016/j.biortech.2011.09.101.

[16] R. Chong, J. Li, Y. Ma, B. Zhang, H. Han, C. Li, Selective conversion of aqueous glucose to value-added sugar aldose on TiO2-based photocatalysts, J. Catal. 314 (2014) 101-108, doi:http://dx.doi.org/10.1016/j.jcat.2014.03.009.

[17] G. Marc1, M. Bellardita, E.I. Garc1, L. Palmisano, S.P. Group, D. Energia Photocatalytic formation of $\mathrm{H} 2$ and value-added chemicals in aqueous glucose (Pt) - TiO 2 suspension, Int. J. Hydrogen Energy 1 (2016) 5934-5947.

[18] M. Bellardita, E.I. García-López, G. Marcì, B. Megna, F.R. Pomilla, L. Palmisano, Photocatalytic conversion of glucose in aqueous suspensions of heteropolyacid-TiO2 compositess, RSC Adv. 5 (2015) 59037-59047, doi:http:// dx.doi.org/10.1039/C5RA09894G.
[19] G.G. Bessegato, T.T. Guaraldo, J.F. de Brito, M.F. Brugnera, M.V.B. Zanoni, Achievements and Trends in Photoelectrocatalysis: from Environmental to Energy Applications, Electrocatalysis 6 (2015) 415-441, doi:http://dx.doi.org/ 10.1007/s12678-015-0259-9.

[20] A. Ghicov, P. Schmuki, Self-ordering electrochemistry: a review on growth and functionality of TiO2 nanotubes and other self-aligned $\mathrm{MO}(\mathrm{x})$ structures, Chem. Commun. (Camb) (2009) 2791-2808, doi:http://dx.doi.org/10.1039/b822726h.

[21] G.G. Bessegato, T.T. Guaraldo, M.V.B. Zanoni, Enhancement of Photoelectrocatalysis Efficiency by Using Nanostructured Electrodes, Mod. Electrochem. Methods Nano Surf. Corros. Sci. InTech 2014 (2016) 271-320, doi: http://dx.doi.org/10.5772/58333.

[22] T.T. Guaraldo, T.B. Zanoni, S.I.C. de Torresi, V.R. Gonçales, G.J. Zocolo, D.P. Oliveira, et al., On the application of nanostructured electrodes prepared by Ti/ TiO2/WO3 template: A case study of removing toxicity of indigo using visible irradiation, Chemosphere 91 (2013) 586-593, doi:http://dx.doi.org/10.1016/j. chemosphere.2012.12.027.

[23] F.M.M. Paschoal, L. Nuñez, M.R. De Vasconcelos Lanza, M.V.B. Zanoni, Nitrate Removal on a $\mathrm{Cu} / \mathrm{Cu} 2 \mathrm{O}$ Photocathode under UV Irradiation and Bias Potential, J. Adv. Oxid. Technol. 16 (2013) 63-70.

[24] M.F. Brugnera, M. Miyata, C.Q. Fujimura Leite, M.V.B. Zanoni, Silver ion release from electrodes of nanotubes of TiO2 impregnated with Ag nanoparticles applied in photoelectrocatalytic disinfection, J. Photochem. Photobiol. A Chem. 278 (2014) 1-8, doi:http://dx.doi.org/10.1016/j.jphotochem.2013.12.020.

[25] J.C. Cardoso, C.A. Grimes, X. Feng, X. Zhang, S. Komarneni, M.V.B. Zanoni, et al., Fabrication of coaxial TiO2/Sb2S3 nanowire hybrids for efficient nanostructured organic-inorganic thin film photovoltaics, Chem. Commun. 48 (2012) 2818-2820, doi:http://dx.doi.org/10.1039/c2cc17573h.

[26] W.Y. Gan, D. Friedmann, R. Amal, S. Zhang, K. Chiang, H. Zhao, A comparative study between photocatalytic and photoelectrocatalytic properties of Pt deposited TiO2 thin films for glucose degradation, Chem. Eng. J. 158 (2010) 482-488, doi:http://dx.doi.org/10.1016/j.cej.2010.01.030.

[27] A. Devadoss, P. Sudhagar, C. Ravidhas, R. Hishinuma, C. Terashima, K. Nakata, et al., Simultaneous glucose sensing and biohydrogen evolution from direct photoelectrocatalytic glucose oxidation on robust $\mathrm{Cu} 2 \mathrm{O}-\mathrm{TiO} 2$ electrodes, Phys. Chem. Chem. Phys. 16 (2014) 21237-21242, doi:http://dx.doi.org/ 10.1039/C4CP03262D.

[28] Y. Zhang, G. Zhao, H. Shi, Y.N. Zhang, W. Huang, X. Huang, et al., Photoelectrocatalytic glucose oxidation to promote hydrogen production over periodically ordered TiO2 nanotube arrays assembled of Pd quantum dots, Electrochim. Acta 174 (2015) 93-101, doi:http://dx.doi.org/10.1016/j. electacta.2015.05.094.

[29] J.C. Colmenares, A. Magdziarz, Room temperature versatile conversion of biomass-derived compounds by means of supported TiO2 photocatalysts, J. Mol. Catal. A Chem. 366 (2013) 156-162, doi:http://dx.doi.org/10.1016/j. molcata.2012.09.018.

[30] W. Zmudzinski, Preliminary results os glucose oxidation by photocatalysis on Titanium Dioxide, Physicochem. Probl. Miner. Process. 45 (2010) 141-151.

[31] M. Kordowska-Wiater, Production of arabitol by yeasts: current status and future prospects, J. Appl. Microbiol. 119 (2015) 303-314, doi:http://dx.doi.org/ $10.1111 /$ jam.12807.

[32] B. Zhou, J. Song, T. Wu, H. Liu, C. Xie, G. Yang, et al., Simultaneous and selective transformation of glucose to arabinose and nitrosobenzene to azoxybenzene driven by visible-light, Green Chem. 18 (2016) 3852-3857, doi:http://dx.doi. org/10.1039/C6GC00943C.

[33] O.V. Singh, R. Kumar, Biotechnological production of gluconic acid: Future implications, Appl. Microbiol. Biotechnol. 75 (2007) 713-722, doi:http://dx. doi.org/10.1007/s00253-007-0851-x.

[34] J. Gullberg, P. Jonsson, A. Nordström, M. Sjöström, T. Moritz, Design of experiments: an efficient strategy to identify factors influencing extraction and derivatization of Arabidopsis thaliana samples in metabolomic studies with gas chromatography/mass spectrometry, Anal. Biochem. 331 (2004) 283295, doi:http://dx.doi.org/10.1016/j.ab.2004.04.037.

[35] S.C. Moldoveanu, V. David, Sample Preparation in Chromatography, Elsevier, 2002, doi:http://dx.doi.org/10.1016/S0301-4770(02)80019-7.

[36] C. Kim, S. Kim, J. Choi, J. Lee, J. Soo, Y. Sung, et al., Electrochimica Acta Blue TiO 2 Nanotube Array as an Oxidant Generating Novel Anode Material Fabricated by Simple Cathodic Polarization, Electrochim. Acta 141 (2014) 113-119, doi: http://dx.doi.org/10.1016/j.electacta.2014.07.062.

[37] M. Cho, H. Chung, W. Choi, J. Yoon, Linear correlation between inactivation of E. coli and $\mathrm{OH}$ radical concentration in $\mathrm{TiO} 2$ photocatalytic disinfection, Water Res. 38 (2004) 1069-1077, doi:http://dx.doi.org/10.1016/j.watres.2003.10.029.

[38] M.E. Simonsen, J. Muff, L.R. Bennedsen, K.P. Kowalski, E.G. Sogaard, Photocatalytic bleaching of p-nitrosodimethylaniline and a comparison to the performance of other AOP technologies, J. Photochem. Photobiol. A Chem. 216 (2010) 244-249, doi:http://dx.doi.org/10.1016/j.jphotochem.2010.07.008.

[39] B. Tan, Y. Zhang, M. Long, Large-scale preparation of nanoporous TiO2 film on titanium substrate with improved photoelectrochemical performance, Nanoscale Res Lett. 9 (2014) 190-196, doi:http://dx.doi.org/10.1186/1556276X-9-190.

[40] M.F. Brugnera, K. Rajeshwar, J.C. Cardoso, M.V.B. Zanoni, Bisphenol A removal from wastewater using self-organized $\mathrm{TIO}(2)$ nanotubular array electrodes, Chemosphere 78 (2010) 569-575, doi:http://dx.doi.org/10.1016/j. chemosphere.2009.10.058.

[41] G.G. Bessegato, J.C. Cardoso, M.V.B. Zanoni, Enhanced photoelectrocatalytic degradation of an acid dye with boron-doped TiO2 nanotube anodes, Catal Today 240 (2015) 100-106. http://dx.org/con10.1016/j.cattod.2014.03.073. 
[42] R. López, R. Gómez, Band-gap energy estimation from diffuse reflectance measurements on sol-gel and commercial TiO2: a comparative study, J. Sol-Gel Sci. Technol. 61 (2012) 1-7, doi:http://dx.doi.org/10.1007/s10971-011-2582-9.

[43] J.J. Sene, W.A. Zeltner, M.A. Anderson, Fundamental photoelectrocatalytic and electrophoretic mobility studies of TIO2 and V-doped TIO2 thin-film electrode materials, J. Phys. Chem. B 107 (2003) 1597-1603, doi:http://dx.doi.org/ 10.1021/jp026317y.

[44] M.V.B. Zanoni, J.J. Sene, M.A. Anderson, Photoelectrocatalytic degradation of Remazol Brilliant Orange 3R on titanium dioxide thin-film electrodes, J. Photochem. Photobiol. A Chem. 157 (2003) 55-63, doi:http://dx.doi.org 10.1016/S1010-6030(02)00320-9.
[45] J. Herrmann, Heterogeneous photocatalysis: fundamentals and applications to the removal of various types of aqueous pollutants, Catal. Today 53 (1999) 115 129, doi:http://dx.doi.org/10.1016/S0920-5861(99)00107-8.

[46] X. Fu, J. Long, X. Wang, D. Leung, Z. Ding, L. Wu, et al., Photocatalytic reforming of biomass: A systematic study of hydrogen evolution from glucose solution, Int. J. Hydrogen Energy 33 (2008) 6484-6491, doi:http://dx.doi.org/10.1016/j. ijhydene.2008.07.068.

[47] M.-H. Du, J. Feng, S.B. Zhang, Photo-Oxidation of Polyhydroxyl Molecules on TiO2 Surfaces: From Hole Scavenging to Light-Induced Self-Assembly of TiO2 -Cyclodextrin Wires, Phys. Rev. Lett. 98 (2007) 66102, doi:http://dx.doi.org/ 10.1103/PhysRevLett.98.066102. 